\title{
Applications of cellulose-based agents for flocculation processes: a bibliometric analysis
}

\author{
Alejandro Barrero-Fernández • Roberto Aguado • Ana Moral • \\ Celeste Brindley $\cdot$ Menta Ballesteros $(\mathbb{D}$
}

Received: 21 May 2021 / Accepted: 28 July 2021

(C) The Author(s) 2021, corrected publication 2021

\begin{abstract}
Not surprisingly, cellulose-based agents for wastewater treatments, and more precisely for coagulation-flocculation processes, raise growing interest, boosted not only by the high availability, functionality, renewability, and biodegradability of cellulose, but also by the outstanding performance of their derivatives. The analysis of 460 publications including review papers, research articles and book chapters, among others, reveals a multidisciplinary approach, where the fields Materials Science, Chemistry, Chemical Engineering and Environmental Science play a major role. In terms of institutions, some of the most relevant contributors are the Wuhan University, Zhejiang Sci-Tech University, Universidad Complutense de Madrid, to name a few. The
\end{abstract}

Supplementary Information The online version contains supplementary material available at https://doi.org/10.1007/s10570-021-04122-z.

A. Barrero-Fernández · A. Moral · M. Ballesteros $(\square)$

Molecular Biology and Biochemical Engineering

Department, Universidad Pablo de Olavide, Ctra. de

Utrera km 1, 41013 Seville, Spain

e-mail: mmbalmar@upo.es

R. Aguado

Department of Chemistry, CQC, Universidade de

Coimbra, Rua Larga, 3004-535 Coimbra, Portugal

C. Brindley

Department of Chemical Engineering, Universidad de Almería, La Cañada de San Urbano s/n, 04120 Almería, Spain most relevant journals were found to be Carbohydrate Polymers, International Journal of Applied Polymer Science and Cellulose. An analysis of 332 keywords allowed us to classify works into three major clusters (besides two minor ones): one mostly defined by cellulose and coagulation; a second one championed by flocculation and cellulose derivatives; and a third one including wastewater treatment and polysaccharides. While the evolution of the scientific production leaves little doubt about it, as depicted in this bibliometric study, this is the first work providing an in-depth assessment and classification of the literature on cellulose for particle aggregation purposes.

Keywords Bibliometric study - Cellulose · Coagulation-flocculation - Wastewater treatment

\section{Introduction}

Every day, manufacturing industries produce large volumes of wastewater that, due to the presence of barely biodegradable and persistent contaminants, alter the physical, chemical and biological properties of natural water bodies (Teles et al. 2020). Some of these contaminants are also harmful to human health (Kasonga et al. 2021). Remediation techniques, whose choice depends on the type of wastewater, include, among others, sedimentation, ionic exchange, biodegradation, adsorption on activated 
carbon, filtration, and chemical oxidation. Usually, none of such methods can offer a stand-alone solution and they need to be continuously revised, complemented and improved to address the new emerging contaminants (Verma et al. 2012; Teles et al. 2020).

Undoubtedly, coagulation-flocculation is one of the most widely used wastewater treatment techniques, aiming to reduce turbidity, colour and organic matter levels by aggregation of small or colloidal particles (Matilainen et al. 2010). These terms, coagulation and flocculation are sometimes used interchangeably and/or ambiguously (Xiao et al. 2015). For the sake of accuracy and in agreement with other authors (Al-Risheq et al. 2021) we henceforth define coagulation as the destabilization of a suspension of particles, whereas flocculation is the aggregation of destabilized particles. By reducing the electrostatic repulsion between microparticles, their size geometrically increases, and thus sediment with ease or become readily treatable by other kinds of solid-liquid separation (Matilainen et al. 2010). Depending on the nature of the agent, this loss of electrostatic repulsion can be attained by chemical or organic coagulation. Chemical coagulation, based on the use of inorganic compounds, strongly depends on many variables such as the dosing time, the $\mathrm{pH}$, and the concentration of the inorganic salts ( $\mathrm{Li}$ et al. 2021). Hence, it is difficult to predict the behaviour of a certain chemical coagulant in real complex environments.

Organic flocculation, on the other hand, usually involves biomolecules of natural origin and attains denser and bigger flocs, which may imply a more cost-effective solution (Renault et al. 2009). Besides improving the coagulation process in itself, some other advantages include more biodegradability and less toxicity to the environment (Bolto and Gregory 2007). It is easy to see why, among the biological macromolecules that can be used as main agents or at least as adjuvants in coagulation-flocculation processes, cellulose derivatives play a major role. Firstly, cellulose is highly available, being the most abundant biopolymer on Earth (Peng et al. 2020). Secondly, like any other hydroxy polymer, it can be chemically modified towards different functional groups, cationic or anionic, hydrophilic or hydrophobic, etc. (Moral et al. 2015; Aguado et al. 2019). Thirdly, their glycosidic bonds are chemically stable, but cleavable by many microorganisms, granting cellulose versatility and biodegradability.

An in-depth bibliometric analysis will allow us to estimate the extent of interest in cellulose derivatives in wastewater treatments. This valuable tool, which has proved its usefulness in the context of coagulation-flocculation processes and other water remediation techniques (Zhang et al. 2020; Demir and Sharma 2021), helps researchers in relating scientific production and industrial development, evaluating the main trends in the generation of knowledge, and identifying the main contributors (Zhang et al. 2020). While the timely bibliometric study by Zhang et al. (2020) on agents for sludge removal mentions polysaccharides such as starch and chitosan (Zhang et al. 2020), cellulose is left out the picture and, for that matter, the vast literature on cellulose-based agents for coagulation-flocculation is yet to be analysed.

We aim to provide researchers and manufacturers with a thorough and systematic analysis of the scientific production on cellulose and its derivatives in wastewater treatments, particularly for particle aggregation purposes. In order to show the growing interest in this topic, trends of cellulosic coagulants, flocculants and/or adjuvants are analysed. More specifically, the methodology encompasses Scopusindexed publications (studying both journals and papers therein), books or book chapters and conferences, if they are accessible through the keywords that define the scope of this article. This paper seeks to assess the evolution of the scientific production on the topic, to classify it by type of publication and subject area, and to identify the main authors and institutions involved. These tasks manifest the potential of the knowledge gathered to evaluate and improve the current industrial processes, their environmental impact, and the social perception thereof.

\section{Methodology}

Searching process

The strategy chosen to develop this bibliometric analysis involves the search engine of Elsevier's database Scopus, as chosen elsewhere (Mongeon and Paul-Hus 2016), given that it encompasses more publications than ISI Web of Knowledge and, at the 
same time, grants the fulfilment of peer review and all other essential requirements of scientific practice.

Search was limited to dates comprised between 1975 and 2020, using the keyword string TITLE-ABS$K E Y$ (cellulose AND (coagulant OR flocculant)), obtaining 460 matches. We excluded non-related areas, e.g., medicine and odontology, which fall far from the scope of this work, even though they fulfilled the search requirements.

\section{Data analysis}

Scopus matches were processed to extract the data that was required to analyse the number of publications by year, the distribution of publications by affiliation and country, the universities and funding institutions accounting for most publications, the journals containing most publications and related citations, and the most relevant authors. Furthermore, the present work particularly emphasised the importance of the keywords used in the scientific literature.

For the analysis of keywords, we acknowledged that some terms can be used with the same meaning, such as bacteria and bacterium. Moreover, terms that could not contribute to the study were discarded (e.g., article). For the same reason, while the use of paper as material was accepted, the use of paper as document was obviously rejected. This analysis encompassed keywords that appeared at least 5 times, obtaining a map which comprised a total of 332 terms. These terms could be classified into 5 groups or clusters.

In order to consider an association of institutions as a scientific community, we inquired whether or not such association implied a tighter collaboration than the ones between each of those institutions and the rest of the research network. Scientific communities, attending to specific keywords in each case, were determined by means of two software packages: VOSviewer (Leiden University and CWTS), which allows for editing graphs in such a way that links between institutions or countries are shown as nodes, meaning tight collaboration. Likewise, the software OpenRefine (open source) was generally used to process the raw data provided by the search engine.

\section{Results and discussion}

Evolution of scientific production

The number of matches from the search engine, 460 , is deemed suitable for a bibliometric analysis, given that it belongs to the usual range of results in bibliometric studies on similar topics (Zhang et al 2020; Malik et al. 2020). The year 1975 is a proper starting point to assess the progression of the scientific production, as therefrom publications occur on a continuous basis. During the two following decades there are few variations in the publications (Fig. 1). However, from 1995 onwards a change of trend can be observed as references gradually increase, and from 2010 growth is faster, evidencing the rising interest in research on cellulose applications as flocculant and coagulant. These publications are mainly research articles (82\%) written in English (89\%), as can be seen in Figs. S1 and S2 (supplementary material).

Analysis by subject area

As can be seen from Fig. 2, the branch of scientific knowledge accounting for the highest number of publications is Materials Science (22\% of total). Over $80 \%$ was published within five subject areas, which, besides Materials Science, include Chemistry (19\%), Chemical Engineering (16\%), Engineering (14\%) and Environmental Sciences (11\%).

Figure 2 shows how the study of cellulose-based coagulants and flocculants benefits from a

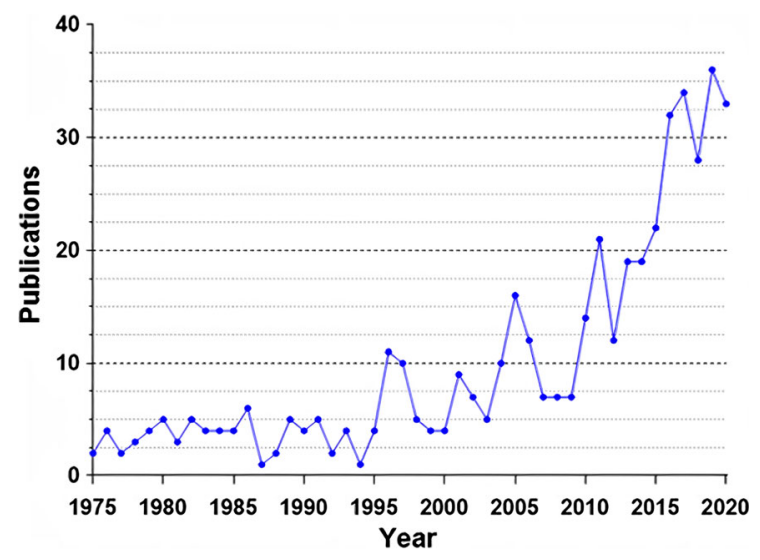

Fig. 1 Number of publications on cellulose based flocculants and coagulants from 1975 to 2020 


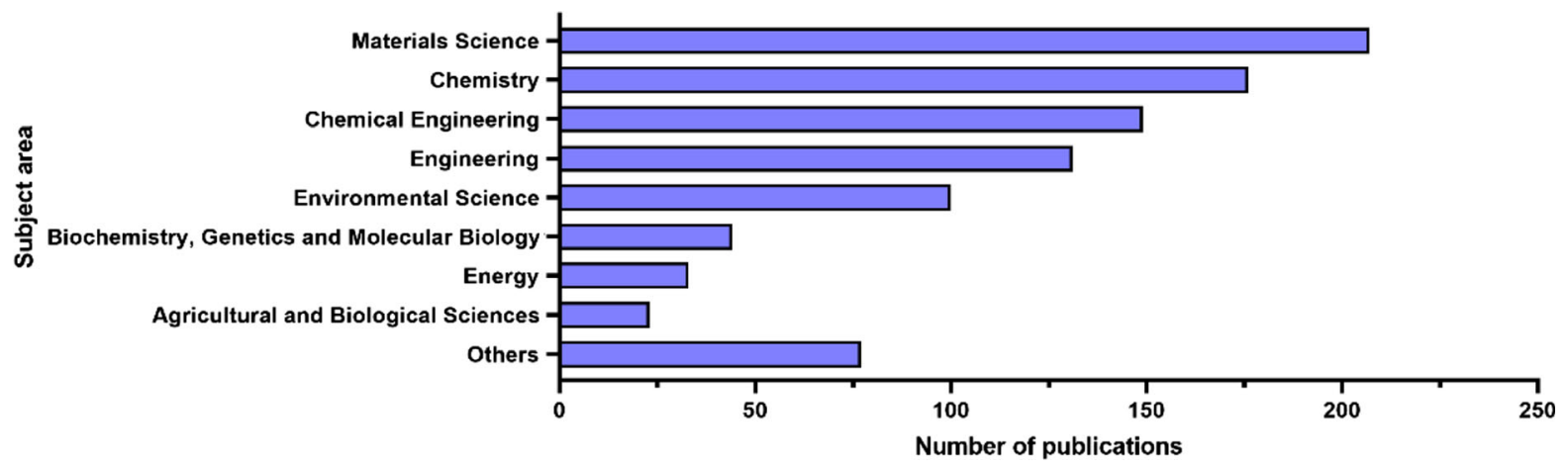

Fig. 2 Subject areas with most articles related to cellulose based flocculants and coagulants

multidisciplinary approach. Strategies often involve physical combinations with other materials (Lee et al. 2012), chemical modifications of cellulose (Koshani et al. 2020) and/or both. As an example of hybrid material, cellulose can be bound to magnetite powder to obtain a valuable flocculation agent for a palm oil mill effluent (Mohamed Noor et al. 2018). Likewise, the presence of $\mathrm{Ag}_{2} \mathrm{O}$ or $\mathrm{TiO}_{2}$ along the cellulose backbone provides usefulness for simultaneous photodegradation (Koshani et al. 2020). As for chemical modifications, they include not only the typical etherifications of hydroxyl groups towards anionic (carboxymethylation) or cationic (quaternary ammonium moieties) derivatives, but also more inspired solutions. For instance, seeking the performance of polyacrylamides, which are poorly biodegradable, and at the same time the biodegradability of polysaccharides, acrylamide units can be grafted onto carboxymethyl cellulose (Miyata et al. 1975). All things considered, Materials Science and Chemistry are mainly found in terms of strategy, while Environmental Science and Engineering encompass frequent objectives of coagulation-flocculation, namely environmental concerns and the need for treating industrial effluents. We particularly remark the abundance of reviews within the area of Environmental Science. Such reviews mainly study the application of different wastewater treatments to grant the safe disposal of effluents or to make water drinkable, comparing innovative proposals to current methods (Matilainen et al. 2010; Verma et al. 2012; Lee et al. 2014; Teh et al. 2016; Wei et al. 2018). Allegedly, and considering they can be prepared in a wide variety of ways (powder, suspension, solution, etc.), cellulose-based agents are compatible with the existing wastewater treatment technologies (Oyewo et al. 2020).

While most research and review papers deal with flocculation in the context of wastewater treatments, the importance of cell flocs in microbiological systems should not be disregarded. It has been shown, for instance, that the flocculation of cellulose-producing bacteria is enhanced by cellulose itself, and thus the biotechnologist often needs to choose an additive, such as carboxymethyl cellulose, to disperse fibers (Andrade et al. 2019). This kind of consideration partly explains the contribution of Biology to the topic.

Ranking of countries, institutions, authors, and journals by number of publications

As can be seen from Fig. 3, the main contributor to the scientific production in relation to the use of cellulose as coagulant and flocculant is China, with over 100 publications, which accounts for more than twice the number of publications of the second most prolific country: Japan. The USA, Canada and India come next, with over 25 publications each. China is also the country with the highest number of institutions that carry out research in this area as well as the biggest funder of this research area, as can be seen in figures S3 and S4, respectively.

To analyse the main contributors to research on cellulosic flocculants and coagulants, the ten most prolific authors in the field have been identified. The classification of the authors and their most relevant contributions are listed in Table 1. As can be seen from Table 1, most of the authors with most publications are in China, which is to be expected 


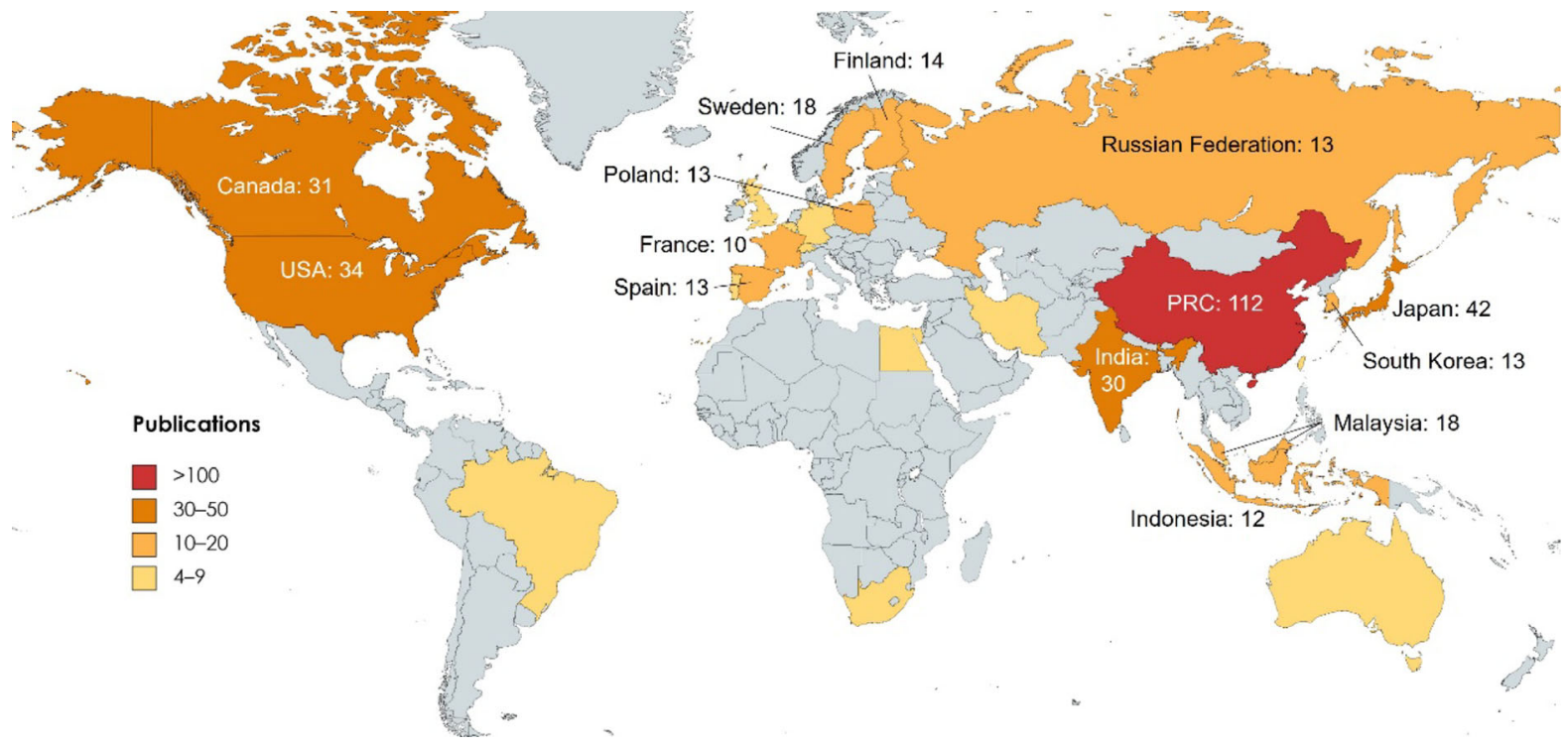

Fig. 3 Worldwide distribution of publications on cellulose-based flocculants and coagulants in countries with more than 10 publications

Table 1 Top-10 authors with the highest number of publications $(\mathrm{N})$ on cellulose-based flocculants and coagulants

\begin{tabular}{|c|c|c|c|c|c|c|}
\hline Author & $\mathrm{N}$ & Institution & & $\mathrm{h}$ & Most contributed topics & ID \\
\hline Zhang, Lina & 14 & Wuhan University & China & 87 & $\begin{array}{l}\text { Purified Rayon; Cellulose } \\
\text { Films }\end{array}$ & 55917992100 \\
\hline Zhang, Yong & 9 & Zhejiang Sci-Tech University & China & 12 & $\begin{array}{l}\text { Flocculants; Polyacrylic Acid; } \\
\text { Sludge Dewatering }\end{array}$ & 57211127995 \\
\hline Zhou, Jinping & 9 & Wuhan University & China & 44 & $\begin{array}{l}\text { Purified Rayon; Cellulose } \\
\text { Films }\end{array}$ & 35387227300 \\
\hline Negro, Carlos & 8 & Universidad Complutense de Madrid & Spain & 32 & $\begin{array}{l}\text { Nanocellulose; Oxidized } \\
\text { Cellulose; Nanowhiskers; } \\
\text { Papermaking }\end{array}$ & 7005434014 \\
\hline Okajima, Kunihiko & 8 & Tokusihima Bunri University & Japan & 26 & $\begin{array}{l}\text { Cellulose; Membranes; } \\
\text { Regenerated Fibers }\end{array}$ & 7202754455 \\
\hline Yang, Xiaogang & 7 & Zhejiang Sci-Tech University & China & 13 & $\begin{array}{l}\text { Flocculants; Polyacrylic Acid; } \\
\text { Sludge Dewatering }\end{array}$ & 56146642400 \\
\hline Liimatainen, Henrikki & 7 & Oulun Yliopisto & Finland & 31 & $\begin{array}{l}\text { Nanocellulose: Cellulose; } \\
\text { Oxidation; Deep Eutectic } \\
\text { Solvents; Water Chemicals }\end{array}$ & 55961077200 \\
\hline Yao, Juming & 6 & Zhejiang Sci-Tech University & China & 33 & $\begin{array}{l}\text { Nanocellulose; Oxidized } \\
\text { Cellulose; Nanowhiskers }\end{array}$ & 56387954400 \\
\hline Blanco, Ángeles & 6 & Universidad Complutense de Madrid & Spain & 17 & $\begin{array}{l}\text { Nanocellulose; Oxidized } \\
\text { Cellulose; Nanowhiskers }\end{array}$ & 56374315900 \\
\hline Yu, Jianyong & 6 & Donghua University & China & 75 & $\begin{array}{l}\text { Air Filters; Fibrous } \\
\text { Membranes; Nanofibers }\end{array}$ & 35185851400 \\
\hline
\end{tabular}

$h:$ h-index 
seen as China is the country with most publications and citations. Table 1 comes to show that in China there are not only many researchers with an interest in the topic, but also that they have authored many publications. Among the institutions, the Chinese universities of Zhejiang Sci-Tech University and Wuhan University stand out, with several authors on the list. Japan is also present in the table, and the presence of Spain and Finland is also noteworthy. The two latter countries count with some very prolific authors, suggesting that in these countries publications originated from a few research groups; the lack of out-standing authors in the USA or India seems to suggest the opposite, that is, publications originated from many disperse research groups.

Figure 4 presents the nine Scopus- and JCRindexed journals with most publications in this area of study. The journals Carbohydrate Polymers, Journal of Applied Polymer Science and Cellulose constitute the top three journals with most publications, with more than 15 each, followed closely by Journal of Membrane Science, with more than 10 publications. The aforementioned journals belong to the first quartile of the area of study that encompasses the publications considered in the year 2019, except for Journal of Applied Polymer Science, which belongs to the second quartile, although it maintains a high $\mathrm{h}$ index, over 150 at the end of 2020 (SJR).

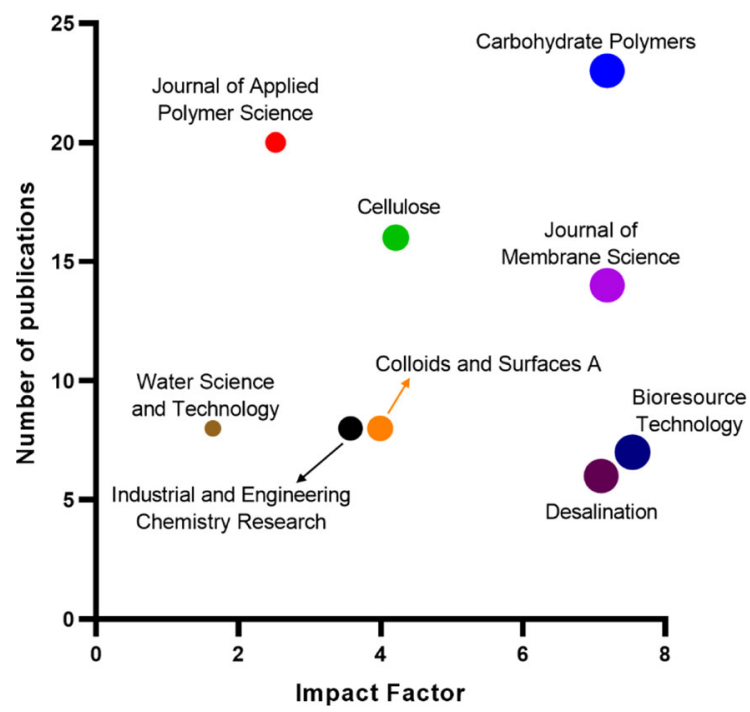

Fig. 4 Journals with most publications on the use of cellulose as coagulant and flocculant, highlighting their impact factor (as of 2020)
Fig. 5 Clusters of keywords that appear with a frequency greater than 5 (a), and evolution of such keywords over time in the period 2005-2020 (b). The color scale indicates the frequency according to the year of publication. (For interpretation of the references to color in this figure, the reader is referred to the web version of this article)

Their impact factors cannot be related to the number of publications, in general terms. In any case, in the same range of impact factors, the number of publications is higher for the journal whose scope addresses the topic more specifically.

\section{Analysis of keywords}

A thoughtful evaluation of keywords implied revising carefully the data, manually discarding vague or unrelated terms. Likewise, synonyms were removed or merged. Figure 5 displays a network of the main keywords in publications dealing with cellulosebased coagulation and/or flocculation. The resulting map contains 169 terms, of which the most frequent are cellulose, flocculation and coagulation. Each node in Fig. 5 presents a keyword in such way that terms in bigger rectangles are more frequent than those in smaller ones. In Fig. 5a, keywords are classified in groups (or clusters) attending to the relations among them, which are shown as lines joining terms that tend to appear in the same work. Broad lines mean a more frequent coexistence than thin lines. Thence 5 clusters were identified. Furthermore, the evolution of their relevance over the period of study (2005-2020) is depicted in Fig. 5b. It is not meaningless that the term flocculation was found with higher frequency than coagulation. Although less frequent, watersoluble polyelectrolytes, including those derived from biopolymers such as cationic cellulose and cellulose sulphonate, may be capable of "direct flocculation" (Chong 2012; Lee et al. 2014), thus not needing a previous destabilizing step, i.e., not needing to rely on the coagulation-flocculation process.

\section{Group 1 (red cluster): materials and target pollutants}

The most remarkable keywords in the red cluster were cellulose (274 appearances) and coagulation (127). This is also the cluster in which most terms 

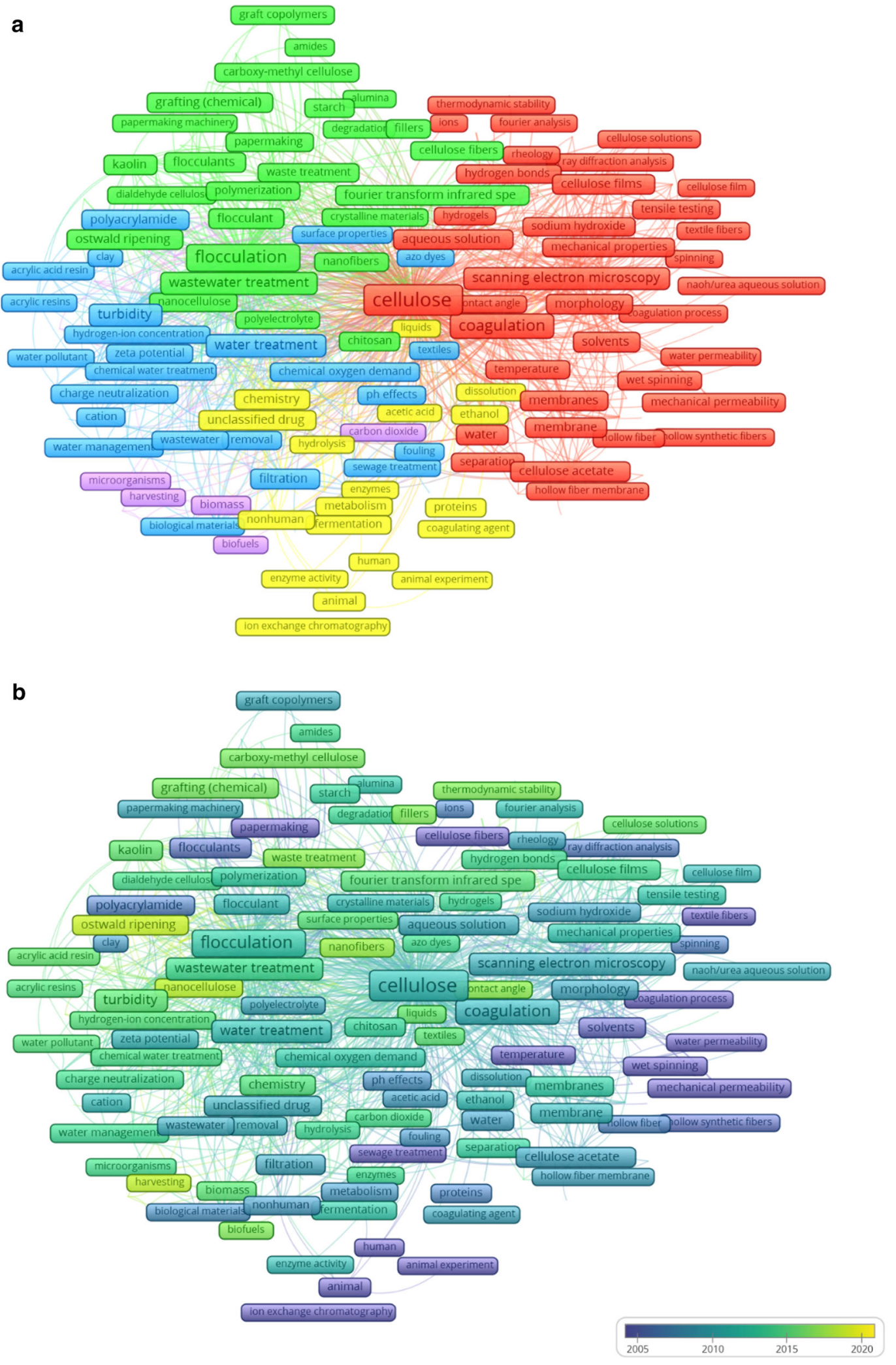
related to Materials Science are included-among others, tensile strength, cellulose films (24), membranes (33), and fibers. Membranes are significantly linked with ultrafiltration (18), in which case those membranes can even discriminate by molecular weight. Interestingly enough, even the keywords solutions, aqueous solution and spinning are often framed in the context of the preparation of different materials, as can be easily seen from a search with the string TITLE-ABS-KEY (cellulose AND coagulation AND (aqueous solution OR solutions OR spinning)). Some of the most relevant and recent papers matching this requirement report the fabrication of permeable membranes (Makarov et al. 2021), protein-repellent coatings (Bračič et al. 2021), antimicrobial packaging (Oliva et al. 2020), and composite fibres with great tensile properties (Song et al. 2018). In these cases, coagulation is not conceived as a wastewater treatment, but as a step in the production process of films or other solid products from aqueous dispersions of cellulose. This also explains the finding of the name of several chemicals as keywords. Sodium hydroxide (17) and urea (22) constitute the most popular system for the dissolution or amorphization of cellulose in aqueous media, while sulphuric acid (10) generates nanocellulose dispersions through the hydrolysis of the least crystalline domains of fibers. Ethanol (10) is the most widely used anti-solvent in the regeneration of cellulose from its dispersed or dissolved form.

The publications with environmental aims that fall into this group, being as valuable as they undoubtedly are, do not usually address real, complex systems. Generally speaking, they target individual pollutants such as methylene blue (Hossain et al. 2021) and different metallic ions including copper(II) (Maaloul et al. 2021), lead(II) (Li et al. 2020) and chromium (VI) (Wang et al. 2020). For such purposes, the contaminant is dissolved in distilled water or in aqueous buffer solutions. On one hand, this is necessary to attain a deep understanding of the physicochemical interaction between pollutants and cellulose. On the other hand, actual wastewater samples for any manufacturing industry do not share this simplicity. Unpredictable interferences come from the presence of many different compounds, the competition between the potential targets, and the difficulties of adjusting factors such as the $\mathrm{pH}$ and the ionic strength. Therefore, we may identify not only a knowledge gap, but also an opportunity arising from the unbalance between the excellent performance reported for these cellulosic materials, frequently hydrogels or membranes (Kanmani et al. 2017; Peng et al. 2020), and the uncertainty of their applicability in real wastewaters.

In any case, looking at the evolution of these keywords with time (Fig. 5b), it is clear that research on most of these topics began before 2010. From this data, it is reasonable to infer that knowing the behaviour of cellulose in aqueous dispersions, even if this knowledge was directed towards sorbents and films (Syverud and Stenius 2009), boosted the research onto the synthesis of soluble cellulose derivatives and their use as flocculants. This concept is key in Group 2, which generally involves more recent insights.

Group 2 (green cluster): flocculation using cellulose derivatives

Whereas in Group 1 coagulation was not framed in coagulation-flocculation treatments as much as in procedures to prepare materials, Group 2 encompasses publications which include flocculation as an essential feature. Whereas in Group 1 we remarked the appearance of solutions and aqueous solution, in Group 2 we found suspensions. Whereas cellulose was highlighted as the key material for membranes, films and other materials, now we must notice the high frequency of cellulose derivatives (42) since, when it comes to flocculation, the insertion of cationic or anionic functional groups is extremely useful for the aims of charge neutralization, electrostatic patching, and bridging (Koshani et al. 2020). Furthermore, $\mathrm{pH}$-independent ionization, such as that achieved with quaternary ammonium groups, broadens the applicability of the potential flocculants.

The appearance of flocculation without coagulation in an article does not necessarily mean that coagulation was not involved. Generally speaking, coagulation and flocculation are found simultaneously in particle aggregation processes. Often, coagulation is deemed a constant factor and only flocculation is evaluated and mentioned, even when in the case of study there are inorganic species that act as coagulants. Cellulose derivatives may be used as flocculants in the presence of inorganic compounds such as calcium chloride, ferric sulphate or 
aluminium chloride (Liu et al. 2014; Peng et al. 2020), i.e., very well-known destabilizers. Other works of similar nature actually include coagulation in the list of keywords, in the abstract or in the title (Suopajärvi et al. 2013; Liu et al. 2014). Noticeably, particle aggregation may involve Ostwald ripening (25) as mechanism.

Dyes (10) are, generally speaking, very popular pollutants in studies seeking to estimate the performance of a flocculation system (Kono and Kusumoto 2015). However, while treating dye containing waters is necessary, the choice of dye as model pollutant has more to do with the ease of quantitative analysis, as its concentration can be simply calculated from the absorbance at a certain wavelength, than with a social or scientific demand for those dyehouse waters. Likewise, the abundance of studies on kaolin (20), which is not the most common filler in papermaking, probably arises from its strongly negative zeta potential, ensuring the successful application of cationic cellulose derivatives (Bratskaya et al. 2006; Aguado et al. 2017).

Nevertheless, many articles framed in Group 2 do not study cellulose-based flocculants for decontamination purposes, but within the scope of the wet end of a paper machine, as additives to the pulp stock or, more precisely, retention aids ( $\mathrm{Li}$ et al. 2015; Aguado et al. 2017). Thus, papermaking (17), one of the major keywords, is of utmost importance, and pulp, additives and retention aids are strongly related to it. While the main goals of flocculation in wet-end chemistry are filler retention and drainage rate, it also has a decisive impact on the composition of the filtrate or white water. Like any other effluent, this stream requires treatment before being discarded, but synthetic flocculants often persist after such treatment.

While biodegradability is alleged as an advantage of cellulose-derived flocculants in 16 articles, only those from the research groups of Yao and Zhang, working with polyacrylamide-grafted cellulose, include biodegradability assays in their experimental section (Zhu et al. 2016; Chen et al. 2020). Most often, however, the biodegradability of cellulose derivatives is taken for granted ignoring the fact that many chemical modifications, such as silanization, cationization and oxidation, lower the biodegradation rate or narrow down the range of suitable conditions for microorganism activity (Kargarzadeh et al. 2017;
Frank et al. 2018). Even in the absence of chemical modifications, researchers must take into account that it is the structure, not the origin of the raw material, what determines biodegradability (Witt et al. 1999). The isolation of the crystalline domains of cellulose, as in the production of nanocrystals, hinders biodegradability in comparison to materials that keep hemicellulose and amorphous regions, which are more prone to microbial attack (Barreto et al. 2010). All things considered, biodegradation studies benefit from discussion on the supramolecular structure of the cellulosic product proposed in each time, and saline, acidic and alkaline media should be considered. Finally, we suggest assessing not only the biodegradability of cellulosic flocculants, but also the toxicity of the products that result from their aerobic or anaerobic decomposition (Vikman et al. 2015).

Group 3 (blue cluster): parameters of wastewater treatments

This keyword cluster is mostly characterised by the occurrence of water treatment (39), turbidity (38), polymers (33), pH (27), particle size (24), filtration (23), effluents (19), pollutant removal (16) and chemical oxygen demand (15), among others. Therefore, publications falling into this cluster aim at water decontamination techniques involving the use of polymers. These polymers include carboxymethyl cellulose (10) and derivatives thereof, but this derivatization, once again, often implies the use of poorly biodegradable polyacrylamides (21) (Feng et al. 2020). It is worth clarifying, however, that this term is more commonly found as a conventional flocculant, chosen for comparison purposes, than as a derivatizing agent for cellulose (Vuoti et al. 2018). In fact, charged flocculants outweigh non-ionic flocculants all along this search. Since the most common cellulose-based agents are carboxymethyl cellulose (anionic), cationic cellulose, cellulose sulphonate (anionic) and combinations with acrylamides (anionic or cationic), it is common to find measurements of zeta potential (12).

A critical approach to these keywords demands some discussion on turbidity, the most widely used parameter to indicate contamination or removal. This can be explained because the most obvious effect of particle aggregation, caused either by coagulationflocculation or by direct flocculation, is a reduction of 
light scattering, i.e., an increase of transparency of the liquid phase. Moreover, legislation and standards on water quality make a prominent use of turbidity as a key indicator (Boyd 2015). However, the absence of pathogens is also a legal requirement in drinking water and, despite the usefulness of flocculation to generate microbial flocs that could be physically separated, the extent of disinfection is seldom reported. In this direction, particle size and chemical oxygen demand are undoubtedly helpful to monitor and evaluate the extent of flocculation, but as unspecific as turbidity. The three of them are quantitative indicators. Therefore, it is difficult to judge if cellulose-based flocculation, as a decontamination technique, is successful when it comes to the removal of emergent pollutants, which are increasingly raising concern among lawmakers. This bibliometric finding encourages the use of chromatography coupled to mass spectrometry (or another kind of detector for qualitative purposes), which is available in most laboratories, to track the removal efficiency for each compound in a real system (Ma et al. 2021).

Most likely, in the elimination of persistent contaminants, particle aggregation complements an advanced technique (Suarez et al. 2009), since wastewater treatment plants are typically unable to target such contaminants through filtration, flotation or sedimentation only. Instead, the pollutant may be adsorbed onto activated carbon (6), oxidized with ferric chloride (5), or exchanged with acrylic resins (7). In those cases, like when working with biological membranes or ultrafiltration devices, coagulationflocculation generally precedes the advanced technique (Zahrim et al. 2011), freeing those methods from suspended solids.

Publications included in Group 3 tend to study more real wastewater streams, frequently industrial waste (5) or sewage (8), than those in the previous keyword groups. This is clearer in the most recent publications (Vuoti et al. 2018). As for the pollutants targeted, there is a wide variety of them, remarkably encompassing phenols (5), azo dyes (5) and metal ions (5), but not addressing pharmaceuticals and other emerging pollutants (PhEPs) which include pharmaceutical compounds and their metabolites, hormones, steroids, personal care products, etc., contained in water at concentrations below ppm level, with harmful effects on human health and, in general, for all ecosystems. Further research is necessary, thus, not only to identify greener alternatives to the functionalization with acrylamides with no major loss of performance, but also to broaden the spectrum of contaminants to be efficiently removed.

\section{Group 4 (yellow cluster): biological applications}

A relatively low number of publications featuring cellulose-based flocculation, or even where cellulose and flocculation are only tangentially related, show biological or biochemical terms: protein (6), enzyme (5), metabolism (11), nonhuman (17), human (7), bacteria (8) and animal (11), along with animal experiment. Less intuitively, ion-exchange chromatography (5) must also be understood in the frame of biological macromolecules, since it has been applied as a high-performance separation technique for protein samples. However, that method is less commonly used in recent papers (Fig. 5b), giving way to affinity chromatography as a more selective technique.

In these cases, a cellulose derivative, such as cellulose acetate phthalate, is used as microbicide or as another kind of biological agent for disease prevention or treatment of animal organs (Otten et al. 2005). Then, the role of flocculation across this cluster ranges from recovering an animal protein from an aqueous suspension (e.g., livestock waters) to synthesizing bacterial cellulose.

\section{Group 5 (purple cluster): micro- and nano- technological applications}

In what should be labelled as another minor cluster, many keywords are related to micro- and nanotechnology: microscopy (5), microfiltration (6), microorganisms (7), nanocrystals (5), nanoparticles (7). In publications which belong to Group 5, interestingly, flocculation may be something to be avoided, rather than promoted. This is the case of $\mathrm{Li}$ et al.'s (2017) cellulose films with silver nanoparticles, whose antimicrobial potential is hindered by flocculation (Li et al. 2017).

Ultimately, there is a wide variety of applications fitting this context. Nonetheless, the main one is harvesting microalgal biomass by means of flocculants, which is indicated by the appearance of harvesting (7), biofuels (6) and microalgae (6), three 
keywords that are found tightly related. In this case, those flocculants are cellulose derivatives or even cellulose nanocrystals (Eyley et al. 2015). It is worth mentioning that papers on this application are relatively recent, thus showing a current research trend (Fig. 5b).

\section{Trends and missing keywords}

Other than cellulose, coagulation and flocculation, $i$. $e$, the terms of the search string, the nine main keywords are presented in Fig. 6, showing their key statistics. Scanning electron microscopy is the most frequently mentioned technique along the 460 publications (Fig. 6b) and the most popular method to analyze morphology and the structure of membranes. Besides turbidity, which is closely related to solutions and polymers (Fig. 6c), the use of light scattering across particle suspensions is outweighed by direct imaging.

Figure 6a displays the year of highest occurrence of each of the main keywords. Interestingly, a shift from solutions (2006), frequently meaning laboratorial aqueous systems, to wastewater (2014) can be observed. Also, remarkably, even considering the consistent increase in the number of publications on the subject, cellulose derivatives were mostly mentioned back in 2007. In contrast, current trends and future research seem to aim more at nanocelluloses, not necessarily involving chemical modifications, than at etherification or esterification of anhydroglucose units. These seem to be displaced by crosslinking and/or grafting of side chains.

Bibliometric studies are effective in identifying not only the current and past research trends, but also which keywords do not appear in the literature, and thus hinting which fields are not being studied and a

\begin{tabular}{|l|l|}
\hline 2006 & $\cdot$ solutions \\
\hline 2007 & $\cdot$ cellulose derivatives; polymers \\
\hline 2009 & $\cdot$ morphology \\
\hline 2010 & $\cdot$ scanning electron microscopy \\
\hline 2012 & $\cdot$ membranes; tensile strength \\
\hline 2014 & $\cdot$ wastewater treatment \\
\hline 2015 & $\cdot$ turbidity \\
\hline
\end{tabular}

C
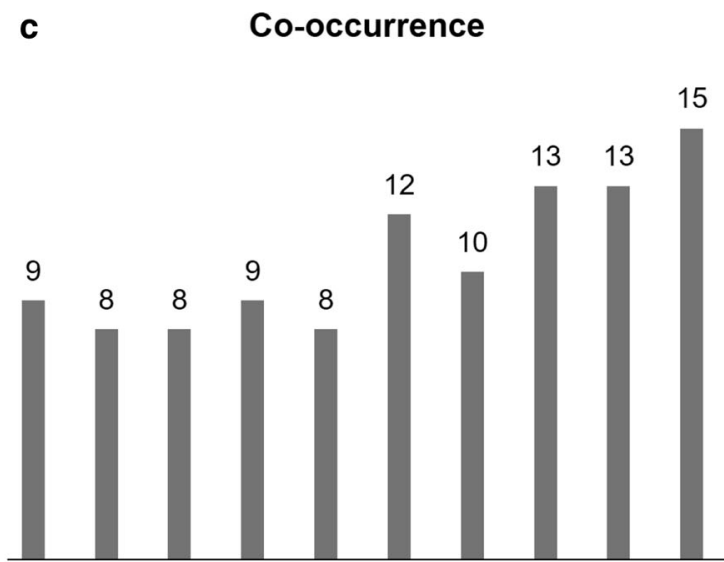

b

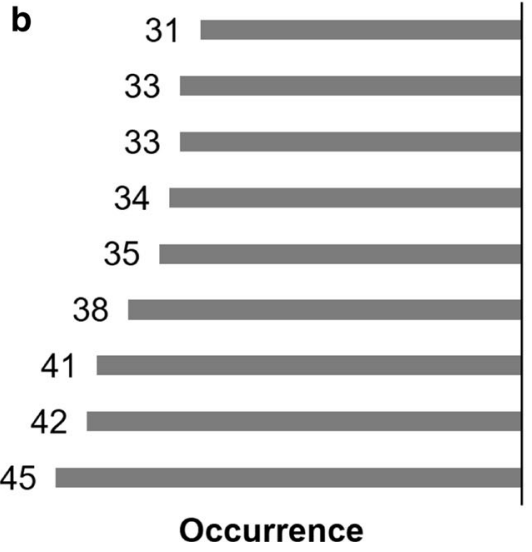

Fig. 6 Selection of nine major keywords, highlighting the year of highest popularity (a), their individual occurrence (b) and their most usual combinations (c) 
which ones deserve special attention. For example, stimuli-responsive polymers or "smart polymers" are macromolecules that are sensitive to a variety of signals, including temperature, $\mathrm{pH}$, light, electrical or magnetic fields, chemicals, etc. In spite of being widely studied in the last decade, they do not appear in any of the clusters in Fig. 5. They have been used in medical applications and they show convincing potential for flocculation processes (Maćczak et al. 2020). Oechsle et al. (2018) prepared a $\mathrm{CO}_{2}$-switchable hydrogel from a suspension of cellulose nanocrystals (CNCs) and its properties make it a promising candidate to be used as flocculant in water treatment (Oechsle et al. 2018). However, much remains to be investigated in this field, which rises as an alternative way to obtain novel cellulose-derived bio-flocculants.

Bioflocculants of cellulosic origin have been used in a wide variety of systems, including turbidity removal from drinking water and municipal wastewater treatment plants, water decolorization in textile industry effluent treatment, flocculation in pulp slurries, treatment of water contaminated by oil spills, etc. (Maćczak et al. 2020). However, in coagulation-flocculation processes in wastewater, there is a lack of pilot plant experiments and techno-economic assessments with coagulants/flocculants from cellulose, as evidenced by the absence of keywords like cost, economic, feasibility or pilot plant. Those studies are necessary to address the (sometimes unpredictable) problems associated with upscaling. In parallel, pilot plant assays allow the accomplishment of a reliable economic analysis of the process. In this sense, the authors believe that future studies should be accompanied by an economic study on the viability of the process, detailing the cost of treatment per cubic meter as a function of the application of the treated water.

\section{Conclusions}

The results of this bibliometric study show that cellulose-based agents for flocculation-coagulation processes is a research area of growing interest with a multidisciplinary approach. There is a wide variety of applications for cellulosic flocculants, but the main one by use and interest is the treatment of wastewater. China, Japan, and the US are the most prolific countries, although Spanish and Finnish authors also stand out on the European continent that deserve special attention when establishing new scientific collaborations in this area. In this field, high-level journals stand out, including Carbohydrate Polymers, Journal of Applied Polymer Science and Cellulose, which gives an idea of the impact of the research.

The analysis of the keywords establishes several scientific communities that indicate the main areas of research being conducted: (1) fabrication of cellulose-based membranes, hydrogels and materials for decontamination; (2) chemical modification of cellulose towards bioflocculants; (3) control and monitoring of wastewater treatment. The extraction of biological macromolecules and applications on nanotechnology account for minor contributions. Moreover, this analysis also reflects some gaps that must be overcome and that can point out for the scientific community which areas need greater efforts to be focused on, such as evaluating in each case the biodegradability of cellulose derivatives instead of taking it for granted. Also, the high functionality of cellulose allows for its modification towards promising, and fortunately trendy as of today, stimuliresponsive polymers. Despite the usefulness of such polymers in solid-liquid systems, including flocculation (e.g., for reversible aggregation as a function of temperature or $\mathrm{pH}$ ), the lack of those terms shows that researchers have not taken that opportunity yet. One opportunity that is being tackled and that will probably constitute a major research trend in the short term, is the use of bioflocculants to harvest microalgae biomass, particularly as feedstock for biofuel generation.

Most water treatment documents focus on the study of environmentally concerning parameters of quantitative nature, such as chemical oxygen demand, total suspended solids, turbidity and color. However, it is necessary to make efforts to study the effectiveness of this type of compounds in eliminating $\mathrm{PhEPs}$ in order to meet the environmental legislation before the wastewater is discharged. In many articles a high-cost effectiveness and low cost of cellulose derivatives is assumed due to the great availability of the biopolymer. Nonetheless, there are no studies detailing the total cost of treatment to make it comparable with existing data in the literature on conventional coagulants/flocculants. Although laboratory-scale studies carried out with cellulosic 
derivatives suggest that this area has great potential, limitations in terms of applicability in drinking water or wastewater treatment plant effluents have not yet been resolved, and extensive research is required to increase viability of cellulose-based flocculants production in a large scale.

\begin{abstract}
Authors' contributions All authors made substantial contributions to the conception of the work, the acquisition and interpretation of data, and writing. All authors approve the manuscript. All authors agree to be accountable for all aspects of the work in ensuring that questions related to the accuracy or integrity of any part of the work are appropriately investigated and resolved.
\end{abstract}

Funding Open Access funding provided thanks to the CRUE-CSIC agreement with Springer Nature. Universidad Pablo de Olavide/CBUA.

Availability of data and material The authors made all data public in the international repository Zenodo.

Code availability Not applicable.

\section{Declarations}

Conflict of interest The authors declare that there is no conflict of interest and that they do not have competing interests.

Ethics approval Not applicable. No studies involving humans and/or animals.

Consent to participate Not applicable. No studies involving humans and/or animals.

Consent for publication Not applicable. No studies involving humans and/or animals.

Open Access This article is licensed under a Creative Commons Attribution 4.0 International License, which permits use, sharing, adaptation, distribution and reproduction in any medium or format, as long as you give appropriate credit to the original author(s) and the source, provide a link to the Creative Commons licence, and indicate if changes were made. The images or other third party material in this article are included in the article's Creative Commons licence, unless indicated otherwise in a credit line to the material. If material is not included in the article's Creative Commons licence and your intended use is not permitted by statutory regulation or exceeds the permitted use, you will need to obtain permission directly from the copyright holder. To view a copy of this licence, visit http://creativecommons.org/licenses/by/4.0/.

\section{References}

Aguado R, Lourenço AF, Ferreira PJ et al (2017) Cationic cellulosic derivatives as flocculants in papermaking. Cellulose. https://doi.org/10.1007/s10570-017-1313-y

Aguado R, Lourenço AF, Ferreira PJT et al (2019) The relevance of the pretreatment on the chemical modification of cellulosic fibers. Cellulose. https://doi.org/10.1007/ s10570-019-02517-7

Al-Risheq DIM, Nasser MS, Qiblawey H et al (2021) Destabilization of stable bentonite colloidal suspension using choline chloride based deep eutectic solvent: optimization study. J Water Process Eng 40:101885. https://doi.org/10. 1016/j.jwpe.2020.101885

Andrade FK, Morais JPS, Muniz CR et al (2019) Stable microfluidized bacterial cellulose suspension. Cellulose 26:5851-5864. https://doi.org/10.1007/s10570-01902512-y

Barreto ACH, Costa MM, Sombra ASB et al (2010) Chemically modified banana fiber: structure, dielectrical properties and biodegradability. J Polym Environ 18:523531. https://doi.org/10.1007/s10924-010-0216-x

Bolto B, Gregory J (2007) Organic polyelectrolytes in water treatment. Water Treat 41:2301-2324. https://doi.org/10. 1016/j.watres.2007.03.012

Boyd CE (2015) Water quality: an introduction, 2nd edn. Springer, Auburn

Bračič M, Mohan T, Kargl R et al (2021) Protein repellent anticoagulative mixed-charged cellulose derivative coatings. Carbohydr Polym 254:117437. https://doi.org/10.1016/ j.carbpol.2020.117437

Bratskaya S, Schwarz S, Petzold G et al (2006) Cationic starches of high degree of functionalization: 12. Modification of cellulose fibers toward high filler technology in papermaking. Ind Eng Chem Res 45:7374-7379

Chen D, Yang X, Chen Y, et al (2020) Study on cellulosebased flocculant from flax yarn waste and its flocculation performance in treating industrial wastewater I 亚麻废纱 制备纤维素基絮凝材料及其混凝工业废水性能.

Fangzhi Xuebao/Journal Text Res 41:88-95. https://doi. org/10.13475/j.fzxb.20190203308

Chong MF (2012) Direct flocculation process for wastewater treatment. In: Sharma SK, Sanghi R (eds) Advances in water treatment and pollution prevention. Springer, Netherlands, pp 201-230

Demir H, Sharma SK (2021) Chapter 1-green chemistry and water remediation: bibliometric study and research applications. In: Sharma SKBT-GC, WRR and A (ed) Advances in green chemistry. Elsevier, New York, pp 133

Eyley S, Vandamme D, Lama S et al (2015) $\mathrm{CO}_{2}$ controlled flocculation of microalgae using $\mathrm{pH}$ responsive cellulose nanocrystals. Nanoscale 7:14413-14421. https://doi.org/ 10.1039/C5NR03853G

Feng X, Wan J, Deng J et al (2020) Preparation of acrylamide and carboxymethyl cellulose graft copolymers and the effect of molecular weight on the flocculation properties in simulated dyeing wastewater under different $\mathrm{pH}$ conditions. Int J Biol Macromol 155:1142-1156. https://doi. org/10.1016/j.ijbiomac.2019.11.081 
Frank BP, Durkin DP, Caudill ER et al (2018) Impact of silanization on the structure, dispersion properties, and biodegradability of nanocellulose as a nanocomposite filler. ACS Appl Nano Mater 1:7025-7038. https://doi. org/10.1021/acsanm.8b01819

Hossain S, Shahruzzaman M, Kabir SF et al (2021) Jute cellulose nanocrystal/poly( $N, N$-dimethylacrylamide-co-3methacryloxypropyltrimethoxysilane) hybrid hydrogels for removing methylene blue dye from aqueous solution. J Sci Adv Mater Devices. https://doi.org/10.1016/j.jsamd. 2021.02.005

Kanmani P, Aravind J, Kamaraj M et al (2017) Environmental applications of chitosan and cellulosic biopolymers: a comprehensive outlook. Bioresour Technol 242:295-303. https://doi.org/10.1016/j.biortech.2017.03.119

Kargarzadeh H, Ioelovich M, Ahmad I et al (2017) Methods for extraction of nanocellulose from various sources. In: Kargarzadeh H, Ahmad I, Thomas S, Dufresne A (eds) Handbook of nanocellulose and cellulose nanocomposites. Wiley, New York, pp 1-49

Kasonga TK, Coetzee MAA, Kamika I et al (2021) Endocrinedisruptive chemicals as contaminants of emerging concern in wastewater and surface water: a review. J Environ Manag 277:111485. https://doi.org/10.1016/j.jenvman. 2020.111485

Kono H, Kusumoto R (2015) Removal of anionic dyes in aqueous solution by flocculation with cellulose ampholytes. J Water Process Eng 7:83-93. https://doi.org/10. 1016/j.jwpe.2015.05.007

Koshani R, Tavakolian M, Van De Ven TGM (2020) Cellulose-based dispersants and flocculants. J Mater Chem B 8:10502-10526. https://doi.org/10.1039/d0tb02021d

Lee KE, Morad N, Teng TT, Poh T (2012) Development, characterization and the application of hybrid materials in coagulation/flocculation of wastewater: a review. Chem Eng J 203:370-386. https://doi.org/10.1016/j.cej.2012.06. 109

Lee CS, Robinson J, Chong MF (2014) A review on application of flocculants in wastewater treatment. Process Saf Environ Prot 92:489-508. https://doi.org/10.1016/j.psep. 2014.04.010

Li G, Fu Y, Shao Z et al (2015) Preparing cationic cellulose derivative in $\mathrm{NaOH} /$ urea aqueous solution and its performance as filler modifier. BioResources 10:7782-7794

Li Y-T, Lin S-B, Chen L-C, Chen H-H (2017) Antimicrobial activity and controlled release of nanosilvers in bacterial cellulose composites films incorporated with montmorillonites. Cellulose 24:4871-4883. https://doi.org/10.1007/ s10570-017-1487-3

Li Y, Xie D, Xiao J et al (2020) Dual responsive copolymersgrafted microfibrillated cellulose composites for removing lead ions from aqueous solution. J Clean Prod 258:120867. https://doi.org/10.1016/j.jclepro.2020. 120867

Li Y, Xu L, Shi T, Yu W (2021) The influence of various additives on coagulation process at different dosing point: from a perspective of structure properties. J Environ Sci 101:168-176. https://doi.org/10.1016/j.jes.2020.08.016

Liu H, Yang X, Zhang Y et al (2014) Flocculation characteristics of polyacrylamide grafted cellulose from phyllostachys heterocycla: anefficient and eco-friendly flocculant. Water Res 59:165-171. https://doi.org/10. 1016/j.watres.2014.04.022

Ma J, Xia W, Zhang R et al (2021) Flocculation of emulsified oily wastewater by using functional grafting modified chitosan: the effect of cationic and hydrophobic structure. J Hazard Mater 403:123690. https://doi.org/10.1016/j. jhazmat.2020.123690

Maaloul N, Oulego P, Rendueles M et al (2021) Biopolymer composite from cellulose nanocrystals of almond (Prunus dulcis) shell as effective adsorbents for $\mathrm{Cu} 2+$ ions from aqueous solutions. J Environ Chem Eng 9:105139. https://doi.org/10.1016/j.jece.2021.105139

Maćczak P, Kaczmarek H, Ziegler-Borowska M (2020) Recent achievements in polymer bio-based flocculants for water treatment. Materials (basEl). https://doi.org/10. 3390/ma13183951

Makarov IS, Golova LK, Vinogradov MI et al (2021) Morphology and transport properties of membranes obtained by coagulation of cellulose solutions in isobutanol. Carbohydr Polym 254:117472. https://doi.org/10.1016/ j.carbpol.2020.117472

Malik S, Khan F, Atta Z, Habib N, Haider MN, Wang N, Alam A, Jambi EJ, Gull M, Mehmood MA, Zhu H (2020) Microalgal flocculation: global research progress and prospects for algal biorefinery. Biotech Appl Biochem 67:52-60. https://doi.org/10.1002/bab.1828

Matilainen A, Vepsäläinen M, Sillanpää M (2010) Natural organic matter removal by coagulation during drinking water treatment: a review. Adv Colloid Interface Sci 159:189-197. https://doi.org/10.1016/j.cis.2010.06.007

Miyata N, Sakata I, Senju R (1975) The effects of the properties of trunk polymers on the flocculating action of graft copolymers. Bull Chem Soc Jpn 48:3367-3371

Mohamed Noor MH, Ngadi N, Luing WS (2018) Synthesis of magnetic cellulose as flocculant for pre-treatment of anaerobically treated palm oil mill effluent. Chem Eng Trans 63:589-594. https://doi.org/10.3303/CET1863099

Mongeon P, Paul-Hus A (2016) The journal coverage of Web of Science and Scopus: a comparative analysis. Scientometrics 106:213-228. https://doi.org/10.1007/s11192015-1765-5

Moral A, Aguado R, Ballesteros M, Tijero A (2015) Cationization of alpha-cellulose to develop new sustainable products. Int J Polym Sci. https://doi.org/10.1155/2015/ 283963

Oechsle A-L, Lewis L, Hamad WY et al (2018) $\mathrm{CO}_{2}$-switchable cellulose nanocrystal hydrogels. Chem Mater 30:376-385. https://doi.org/10.1021/acs.chemmater. $7 \mathrm{~b} 03939$

Oliva C, Huang W, El Badri S et al (2020) Concentrated sulfuric acid aqueous solution enables rapid recycling of cellulose from waste paper into antimicrobial packaging. Carbohydr Polym 241:116256. https://doi.org/10.1016/ j.carbpol.2020.116256

Otten RA, Adams DR, Kim CN et al (2005) Multiple vaginal exposures to low doses of R5 simian-human immunodeficiency virus: strategy to study HIV preclinical interventions in nonhuman primates. J Infect Dis 191:164-173. https://doi.org/10.1086/426452

Oyewo OA, Elemike EE, Onwudiwe DC, Onyango MS (2020) Metal oxide-cellulose nanocomposites for the removal of 
toxic metals and dyes from wastewater. Int $\mathrm{J}$ Biol Macromol 164:2477-2496. https://doi.org/10.1016/j.ijbio mac.2020.08.074

Peng B, Yao Z, Wang X et al (2020) Cellulose-based materials in wastewater treatment of petroleum industry. Green Energy Environ 5:37-49. https://doi.org/10.1016/j.gee. 2019.09.003

Renault F, Sancey B, Badot PM, Crini G (2009) Chitosan for coagulation/flocculation processes-an eco-friendly approach. Eur Polym J 45:1337-1348. https://doi.org/10. 1016/j.eurpolymj.2008.12.027

Song J, Guo J, Zhang S, Gong Y (2018) Properties of cellulose/ Antarctic krill protein composite fibers prepared in different coagulation baths. Int J Biol Macromol 114:334340. https://doi.org/10.1016/j.ijbiomac.2018.03.118

Suarez S, Lema JM, Omil F (2009) Pre-treatment of hospital wastewater by coagulation-flocculation and flotation. Bioresour Technol 100:2138-2146. https://doi.org/10. 1016/j.biortech.2008.11.015

Suopajärvi T, Liimatainen H, Hormi O, Niinimäki J (2013) Coagulation-flocculation treatment of municipal wastewater based on anionized nanocelluloses. Chem Eng J 231:59-67. https://doi.org/10.1016/j.cej.2013.07.010

Syverud K, Stenius P (2009) Strength and barrier properties of MFC films. Cellulose 16:75-85

Teh CY, Budiman PM, Shak KPY, Wu TY (2016) Recent advancement of coagulation-flocculation and its application in wastewater treatment. Ind Eng Chem Res 55:43634389. https://doi.org/10.1021/acs.iecr.5b04703

Teles MNO, Santos BLP, Silva DP et al (2020) A bibliometric description of lignin applicability for the removal of chemical pollutants in effluents. Water Air Soil Pollut. https://doi.org/10.1007/s11270-020-04702-y

Verma AK, Dash RR, Bhunia P (2012) A review on chemical coagulation/flocculation technologies for removal of colour from textile wastewaters. J Environ Manag 93:154168. https://doi.org/10.1016/j.jenvman.2011.09.012

Vikman M, Vartiainen J, Tsitko I, Korhonen P (2015) Biodegradability and compostability of nanofibrillar cellulose-based products. J Polym Environ 23:206-215. https://doi.org/10.1007/s10924-014-0694-3
Vuoti S, Narasimha K, Reinikainen K (2018) Green wastewater treatment flocculants and fixatives prepared from cellulose using high-consistency processing and deep eutectic solvents. J Water Process Eng 26:83-91. https://doi.org/10.1016/j.jwpe.2018.09.003

Wang Y, Yu L, Wang R et al (2020) A novel cellulose hydrogel coating with nanoscale $\mathrm{Fe} 0$ for $\mathrm{Cr}(\mathrm{VI})$ adsorption and reduction. Sci Total Environ. https://doi.org/10. 1016/j.scitotenv.2020.138625

Wei H, Gao B, Ren J et al (2018) Coagulation/flocculation in dewatering of sludge: a review. Water Res 143:608-631. https://doi.org/10.1016/j.watres.2018.07.029

Witt U, Yamamoto M, Seeliger U et al (1999) Biodegradable polymeric materials-not the origin but the chemical structure determines biodegradability. Angew Chemie Int Ed 38:1438-1442. https://doi.org/10.1002/(SICI)15213773(19990517)38:10\%3c1438::AID-ANIE1438\%3e3.0. $\mathrm{CO} ; 2-\mathrm{U}$

Xiao X, Song C, Yue P et al (2015) Synthesizing attapulgitegraft-polyacrylamide flocculant and immobilizing microorganisms to treat low-ammonium water. Desalin Water Treat 56:929-938. https://doi.org/10.1080/ 19443994.2014.941011

Zahrim AY, Tizaoui C, Hilal N (2011) Coagulation with polymers for nanofiltration pre-treatment of highly concentrated dyes: a review. Desalination 266:1-16. https://doi.org/10.1016/j.desal.2010.08.012

Zhang G, Shi Q, Li Q et al (2020) Agents for sludge dewatering in fundamental research and applied research: a bibliometric analysis. J Clean Prod 273:122907. https://doi.org/10.1016/j.jclepro.2020.122907

Zhu H, Zhang Y, Yang X et al (2016) Polyacrylamide grafted cellulose as an eco-friendly flocculant: key factors optimization of flocculation to surfactant effluent. Carbohydr Polym 135:145-152. https://doi.org/10.1016/j.carbpol. 2015.08.049

Publisher's Note Springer Nature remains neutral with regard to jurisdictional claims in published maps and institutional affiliations. 